\title{
The role of organic electron donors in the initiation of BHAS base-induced coupling reactions between haloarenes and arenes
}

\author{
Andrew J. Smith ${ }^{a}$, Darren L. Poole ${ }^{b}$ and John A. Murphy ${ }^{\star a}$, \\ (a) Department of Pure and Applied Chemistry, University of Strathclyde, 295 Cathedral \\ Street, Glasgow G1 1XL, United Kingdom; (b) Flexible Discovery Unit, GlaxoSmithKline \\ Medicines Research Centre, Gunnels Wood Road, Stevenage, SG1 2NY United Kingdom.
}

\begin{abstract}
.
Coupling reactions between haloarenes and arenes (including heteroarenes) that are conducted without added transition metals but in the presence of $\mathrm{KO}^{t} \mathrm{Bu}$ or $\mathrm{NaO}^{t} \mathrm{Bu}$, have been a topic of great interest since their discovery in 2008. Diverse organic structures act as additives that assist these reactions. These additives are converted into organic electron donors by the butoxide base and this leads to initiation of the coupling reactions, which proceed by radical chain mechanisms. This review provides an overview of the initiation stages of these reactions.
\end{abstract}

Keywords: Organic electron donor, potassium tert-butoxide, electron transfer, BHAS coupling, benzyne

\section{Introduction}

Coupling reactions that are catalysed by transition metals, often palladium, are of profound importance in synthetic chemistry. Given the cost of precious metals and the toxicity of metal residues, chemists are very interested in processes that use non-precious transition metals or that avoid transition metals completely. This explains the excitement that surrounded the report of coupling of iodoarenes to heteroarenes by Itami et al. in 2008 (Scheme 1) in the absence of added transition metals. ${ }^{1}$ During the exploration of iridium catalysts in the coupling of iodobenzene $\mathbf{1}$ with pyridine $\mathbf{2}$ to produce product $\mathbf{3}$ in the presence of $\mathrm{KO}^{\mathrm{t}} \mathrm{Bu}$, it was found that the best iridium catalyst gave a comparable result to the reaction with no iridium catalyst present ( $41 \%$ and $39 \%$ yield respectively). The reactions, in the absence of catalysts, were extended to other electron-poor heteroarenes, e.g. pyrazine 5, and were optimised to give excellent yields. By using more substituted iodoarenes e.g. 4, it was established that the carbon involved in the original C-I bond in the haloarene was the carbon used to form the $\mathrm{C}-\mathrm{C}$ bond to the heteroarene. The use of common radical scavengers such 
as TEMPO saw a dramatic decrease in yield (to $<1 \%$ ), leading to the proposal of a radical intermediate in these reactions.

In 2010, the groups of (i) Shi et al., ${ }^{2}$ and (ii) Shirakawa and Hayashi et al. ${ }^{3}$ and (iii) Kwong, Lei et al. ${ }^{4}$ independently reported the use of substoichiometric amounts of organic additives, along with alkali metal tert-butoxides, to promote the transition metal-free coupling of a

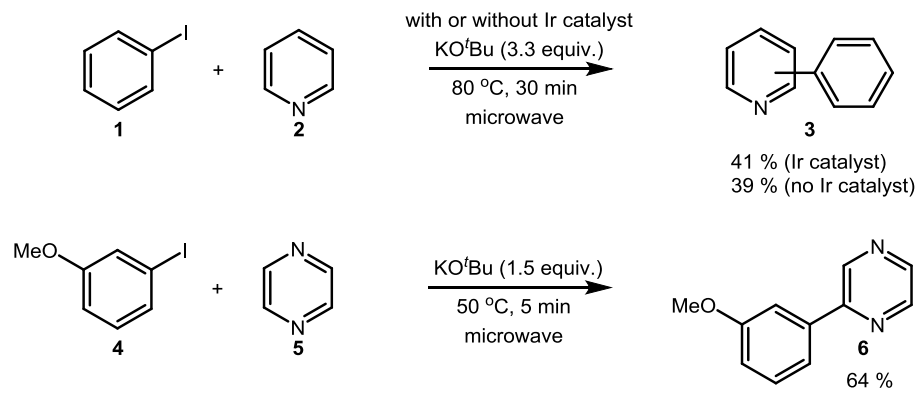

Scheme 1 - Coupling reactions reported by Itami et al. ${ }^{1}$

variety of iodo- and bromo-arenes with arene coupling partners. Kwong, Lei et al. ${ }^{4}$ achieved high yielding couplings using 1,2-diols, 1,2-diamines, amino alcohols and also used the amino acid, proline, to facilitate coupling reactions of haloarenes to arenes in the presence of $\mathrm{KO}^{t} \mathrm{Bu}$. They also showed the involvement of radical anions as intermediates in the mechanism. Shi, and Shirakawa and Hayashi used phenanthroline as an additive. Shi proposed also that radicals were key intermediates in these reactions, although it was not clear how the radicals formed, nor what mechanism led to the coupled product. Shi also reported intramolecular coupling reactions.

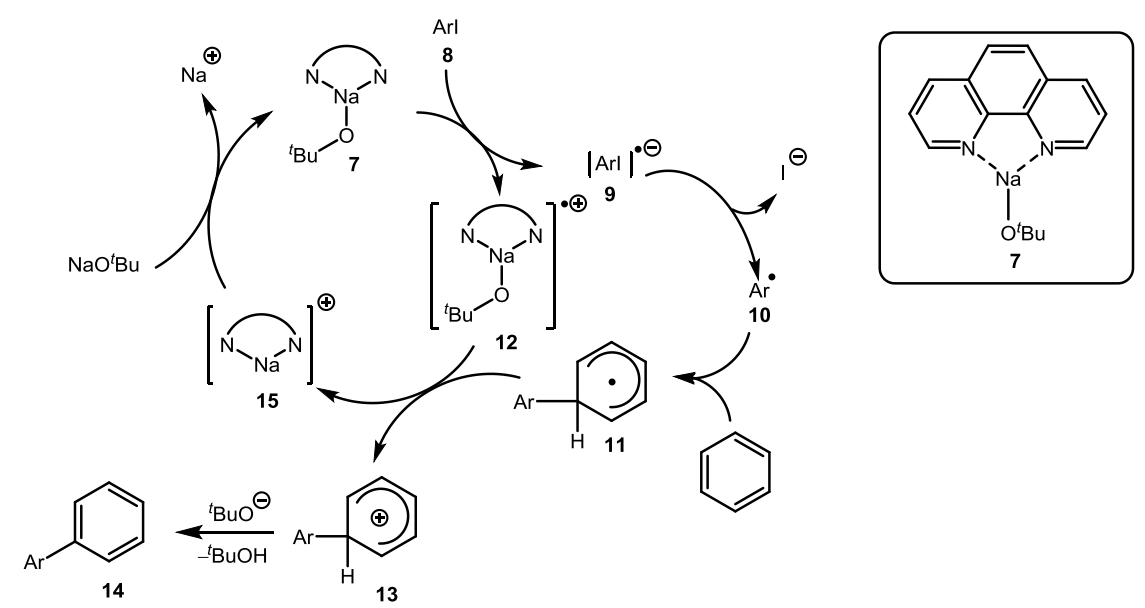

Scheme 2 - Mechanism suggested by Shirakawa, Hayashi et al. ${ }^{3}$

In their publication, it was suggested by Shirakawa and Hayashi that the complex of $\mathrm{NaO}^{t} \mathrm{Bu}$ with phenanthroline $(\mathbf{7}$, Scheme 2$)$ donates a single electron to the aryl halide $\mathbf{8}$ to produce a radical anion $\mathbf{9}$. This then dissociates into an aryl radical $\mathbf{1 0}$ and an iodide anion. Aryl radical 


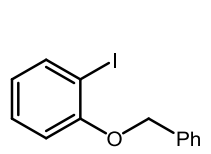

16

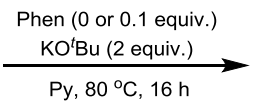

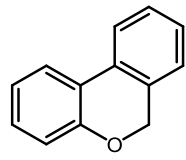

17 with Phen: $77 \%$
without Phen: $50 \%$

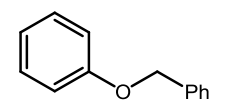

18

with Phen: $4 \%$ without Phen: $18 \%$

Scheme 3 - Charette's intramolecular cyclisations ${ }^{5}$

10 adds to benzene to produce a cyclohexadienyl radical 11 , which is subsequently oxidised by radical cation 12 to produce a tert-butoxide anion, complex 15 and cation 13 . Deprotonation of 13 by tert-butoxide affords coupled product 14 and tert-butanol. The sodium-phenanthroline complex 15 can then react with more sodium tert-butoxide to regenerate 7 and continue the cycle.

Studies by Charette in 2011 also showed intramolecular arylation of 16 with phenanthroline (phen) and $\mathrm{KO}^{t} \mathrm{Bu}$ in pyridine as solvent, affording 17 and 18 (Scheme 3 ). ${ }^{5}$ These reactions also afforded 17 and 18 in the absence of phenanthroline when pyridine was used as solvent, albeit in lower yield. When $\mathrm{KO}^{t} \mathrm{Bu}$ was replaced with $\mathrm{NaO}^{t} \mathrm{Bu}$, no reaction occurred and only starting material was recovered. The authors proposed that this reaction proceeds via electron transfer to the aryl iodide to afford an aryl radical followed by cyclisation, but did not comment on the species responsible for the initial electron transfer.

In 2011, Studer and Curran further explored the mechanism for $\mathrm{KO}^{t} \mathrm{Bu}$-mediated electron transfer reactions. ${ }^{6}$ The common features of these coupling reactions were the coupling of a haloarene to an arene in the presence of $\mathrm{KO}^{t} \mathrm{Bu}$ (or sometimes $\mathrm{NaO}{ }^{t} \mathrm{Bu}$ ) and a nitrogen heterocycle; the heterocycle could either be a substrate heteroarene or simply an additive to the reaction. They proposed a key role for $\mathrm{KO}^{t} \mathrm{Bu}$ in these reactions, leading to the Basepromoted Homolytic Aromatic Substitution (BHAS) mechanism shown in Scheme 4 that is now widely accepted.

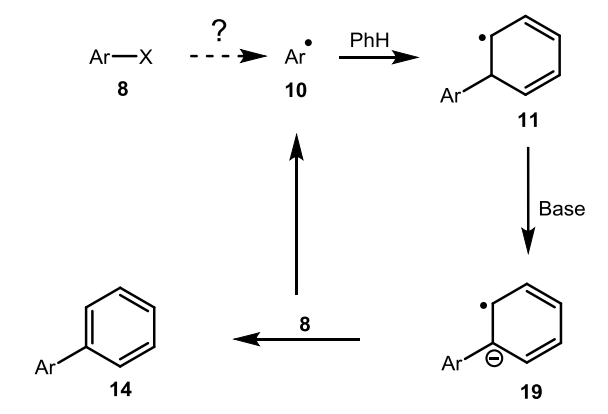

Scheme 4- Studer and Curran's BHAS cycle ${ }^{6}$

Aryl halide $\mathbf{8}$ is transformed to aryl radical $\mathbf{1 0}$ by a mechanism that was unknown at that time. This aryl radical undergoes addition to a molecule of benzene to produce radical $\mathbf{1 1}$, which is deprotonated by potassium tert-butoxide to form radical anion 19 . This is a strong 
electron donor, and so this is a striking example of 'upconversion' of reducing power, arising by deprotonation of a stabilised $\pi$-radical to a highly reactive radical anion where the unpaired electron is housed in a $\pi *$-orbital. ${ }^{7}$ This radical anion can then undergo single electron transfer (SET) to another molecule of 8, producing rearomatised coupled product 14 while regenerating another aryl radical 10, which can propagate the chain. However, the method of initiation of the reaction through initial formation of radical $\mathbf{1 0}$ was still unknown at this point. The initiation of these and related coupling reactions is the focus of this review.
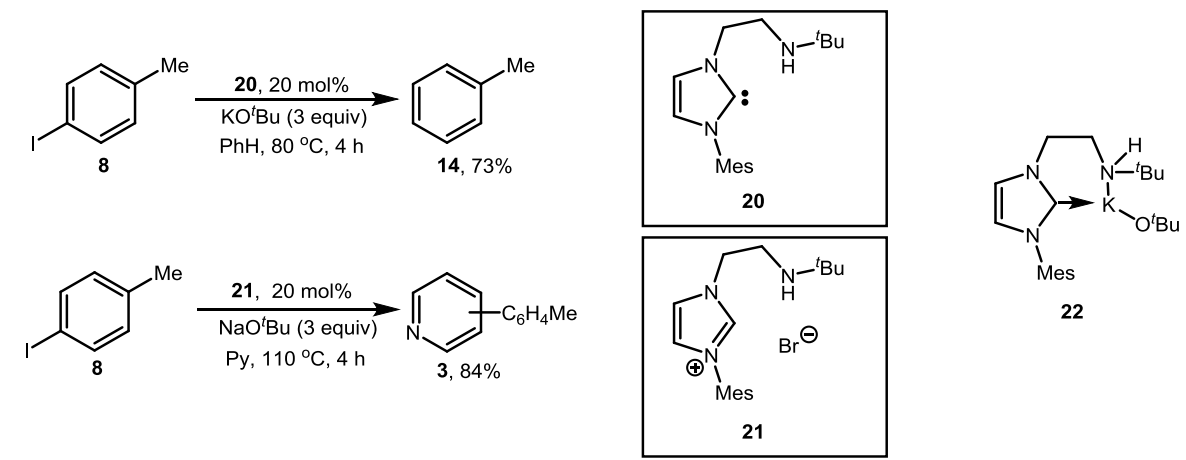

Scheme 5 - Arylation of benzene and pyridine by Chen, Ong et al. ${ }^{8}$

In 2012, Chen, Ong et al. reported the arylation of benzene and pyridine promoted by heterocyclic carbenes (e.g. 20) or their precursor imidazolium salt precursors (e.g. 21). ${ }^{8}$ In this work, iodoarenes $\mathbf{8}$ were coupled to benzene or pyridine using $\mathrm{KO}^{t} \mathrm{Bu}$ or $\mathrm{NaO}^{t} \mathrm{Bu}$ and a heterocyclic carbene or imidazolium salt, to afford the products $\mathbf{1 4}$ and $\mathbf{3}$. Carbene 20 and salt 21 were the most successful examples (Scheme 5). They proposed that the BHAS chemistry is initiated via SET from a complex of the carbene additive with $\mathrm{KO}^{t} \mathrm{Bu}$, e.g. 22.

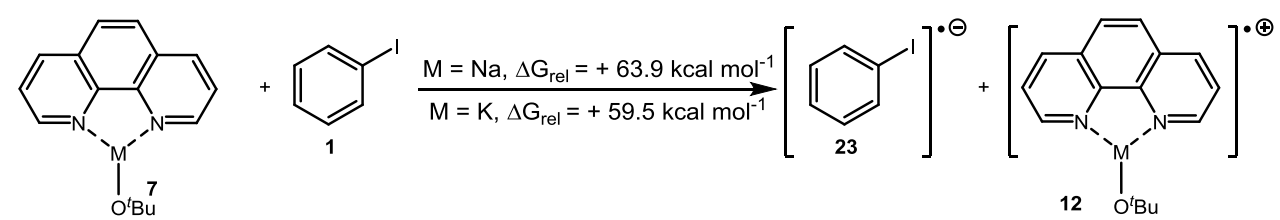

Scheme 6 - Calculations of the thermodynamic barrier for ground-state electron transfer from complex 7 to iodobenzene $1^{9}$

The studies of Chen and Ong with imidazolium salts, and those of Shi and Shirakawa and Hayashi with phenanthroline were of great interest to the Murphy team. Looking at complex $7(\mathrm{M}=\mathrm{Na})$, it was difficult to envisage how it could be a strong electron donor in its ground state - it features three components: (i) an electron-deficient heterocycle, phenanthroline, (ii) a sodium cation and (iii) a tert-butoxide anion, each of which would separately be a very reluctant electron donor. The proposal of $\mathbf{2 2}$ as an electron donor looks to be analogous. (i) An N-heterocyclic carbene, (ii) a potassium cation and (iii) a tert-butoxide anion would be unlikely to undergo electron transfer to aryl halides in the ground state. The common feature 
of these two models 7 and 22 is the complexation of the metal butoxide. It might be considered that this complexation would lead to an enhanced separation of the metal ion from the tert-butoxide anion. This greater exposure of the charged anion in a relatively nonpolar solvent like benzene, might provide some driving force for the butoxide entity to become neutral by transferring an electron, but the size of any such effect needed to be quantified.

Accordingly, in 2014, Tuttle, Murphy et al. reported their studies on the initiation step of the BHAS cycle. ${ }^{9}$ Focusing on complex 7 , they calculated computationally that the free energy change (i.e. the thermodynamic difference, and not the kinetic barrier) for the electron transfer from the sodium ion complex with phenanthroline suggested by Shirakawa and Hayashi (7) to iodobenzene 1 was $\Delta G=+63.9 \mathrm{kcal} \mathrm{mol}^{-1}$, and $\Delta \mathrm{G}=+59.5 \mathrm{kcal} \mathrm{mol}^{-1}$ for the analogous potassium ion case. This ruled out 7 as the source of the initial electron transfer, and suggested that a different species must be produced in situ to cause the electron transfer. Similarly, they were concerned about species 22, arising from precursor imidazolium salt 21.

2 Providing a mechanistic picture for initiation of BHAS coupling through organic electron donors

2.1 Super Electron Donors facilitate the initiation of BHAS coupling while benzynes can provide a slower initiation

Back in 2005 and 2007, Murphy et al. had exploited the reactivity of tetraazafulvalene dimers, formed respectively from treatment of benzimidazolium ${ }^{10}$ and imidazolium salts ${ }^{11}$ with base. In the example in Scheme 7A, the base converts the imidazolium salt 24 into an $\mathrm{N}$-heterocyclic carbene 25, which then nucleophilically attacks the other imidazolium salt within the molecule. A second deprotonation then converts $\mathbf{2 6}$ into the tetraazafulvalene $\mathbf{2 7}$. These 'dimers' were the first neutral ground-state organic molecules to reduce aryl iodides to aryl radicals or aryl anions, and were termed 'super electron donors'. ${ }^{10,11}$ If aryl radicals, generated by compound $\mathbf{2 7}$ on reaction with iodobenzene 1, could achieve coupling to benzene to form biphenyl 28 under BHAS conditions, then, in the first instance, that could allow an alternative interpretation of initiation of radical chemistry in the reactions of Chen and Ong with imidazolium salts, and later might provide a clue to the role of phenanthroline.

The initial test reaction used donor precursor salt $\mathbf{2 4}$, iodobenzene $\mathbf{1}$, and potassium tert-butoxide in benzene (Scheme 7B). The expected coupling product, biphenyl 28, was formed in 80\% yield, (Salt 24 forms electron donor $\mathbf{2 7}$ in the presence of a strong base. This donor then initiates BHAS chemistry by electron transfer to substrate 1). 
Conditions for the formation of 28 from 1 were studied. At $130{ }^{\circ} \mathrm{C}$ for $3.5 \mathrm{~h}$ with 5 mol\% 24 , biphenyl 28 was formed in $80 \%$ yield (Table 1, entry 1 ). ${ }^{9}$ When the reaction temperature was
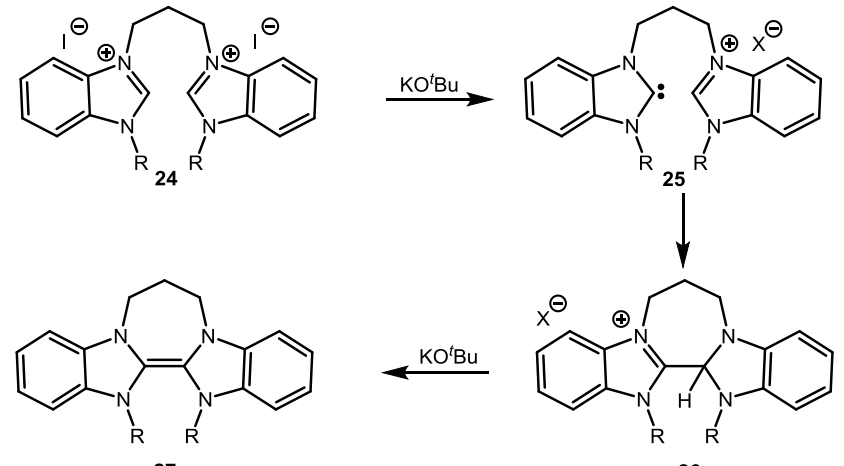

B

27
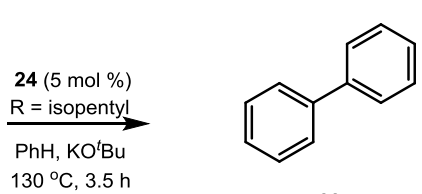

$28(80 \%)$

Scheme 7- Tetraazafulvalenes can initiate coupling of iodobenzene with benzene to produce bipheny $\rho^{9}$

Table 1 - Formation of biphenyl 28 using salt 24 as precursor to electron donor 27

\begin{tabular}{|c|c|c|c|}
\hline Entry & $\mathbf{2 4}(\mathrm{Mol} \%)$ & Temperature & $\mathbf{2 8}(\%)$ \\
\hline $\mathbf{1}$ & 5 & $130^{\circ} \mathrm{C}$ & 80 \\
\hline $\mathbf{2}$ & 5 & $110^{\circ} \mathrm{C}$ & 47 \\
\hline $\mathbf{3}$ & 0 & $130^{\circ} \mathrm{C}$ & 30 \\
\hline $\mathbf{4}$ & 0 & $110^{\circ} \mathrm{C}$ & 27 \\
\hline
\end{tabular}

dropped to $110{ }^{\circ} \mathrm{C}$, the yield dropped to $47 \%$ in the presence of $5 \mathrm{~mol} \%$ disalt 24 . When the reaction was conducted in the absence of disalt $\mathbf{2 4}$, however, biphenyl was still formed but in a much lower yield $\left(30 \%\right.$ at $130{ }^{\circ} \mathrm{C}$ and $27 \%$ at $\left.110{ }^{\circ} \mathrm{C}\right)$. These results showed that the presence of the salt $\mathbf{2 4}$ accelerated the reaction considerably. Murphy et al. therefore learned that an accelerated pathway to the product arose in the presence of the electron donor 27, but an alternative and slower pathway still existed in its absence, i.e. when only $\mathrm{Arl}, \mathrm{PhH}$ and $\mathrm{KO}^{\mathrm{t}} \mathrm{Bu}$ were present.

Considering firstly the slower pathway, benzyne was proposed as the initiator in the absence of the electron donor. This was supported in the literature, where a number of papers had reported the behaviour of benzyne as a 1,2-diradical. ${ }^{12-14}$ This pathway would then see benzyne, 29', generated in very small quantities by the reaction of $\mathrm{KO}^{\mathrm{t}} \mathrm{Bu}$ with iodobenzene 1, add to benzene to give distal diradical 30 (Scheme 8). The aryl radical is the more reactive of the two radicals in $\mathbf{3 0}$. This could undergo rapid addition to another molecule of 


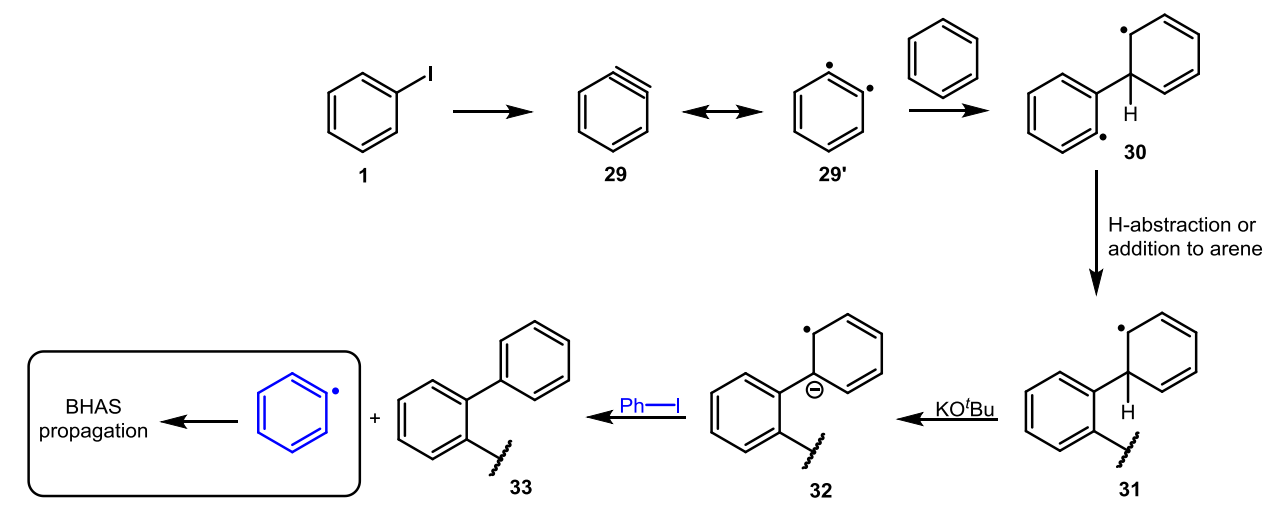

Scheme 8 - Benzyne can initiate BHAS coupling reactions ${ }^{9}$

benzene or hydrogen atom abstraction from benzene to afford 31. Deprotonation would afford radical anion 32 which could then donate an electron to iodobenzene to form the phenyl radical that starts the propagation stage of the BHAS cycle. In this way, benzyne is involved in the initiation step, but not in the propagation steps. Provided that the rate of initiation is much slower than the propagation rate, no products derived from benzyne will be detected in the products.

To test this proposal and to separate the faster electron-donor induced coupling from the slower benzyne-induced coupling, substrate 2,6-dimethyliodobenzene 34, was selected, which is blocked in the ortho positions by methyl groups. No reaction occurred ${ }^{9}$ in additivefree conditions, supporting the theory that this slower coupling reaction was occurring via a benzyne mechanism. When the reaction was repeated in the presence of the salt $\mathbf{2 4}$, precursor of donor $\mathbf{2 7}$ in situ, the expected coupling product $\mathbf{3 6}$ was formed in 5\% yield, along with 19\% biphenyl 28 and recovered starting material 34 (36\%) (Scheme 9). The formation of $\mathbf{2 8}$ from this reaction is explained in Scheme 10. Electron transfer from donor 27 to substrate $\mathbf{3 4}$ affords radical $\mathbf{3 7}$ and an iodide anion. The 2,6-dimethylphenyl radical $\mathbf{3 7}$ is too sterically hindered to undergo efficient $\mathrm{C}-\mathrm{C}$ bond formation with benzene, and is more likely to undergo hydrogen atom abstraction from benzene to form the volatile $m$-xylene $\mathbf{3 8}$ and phenyl radical 39, which can undergo addition to benzene to form biphenyl 28 (Scheme $10)$ by BHAS chemistry. The ratio of products $28(19 \%): 36(5 \%)$ was noted.

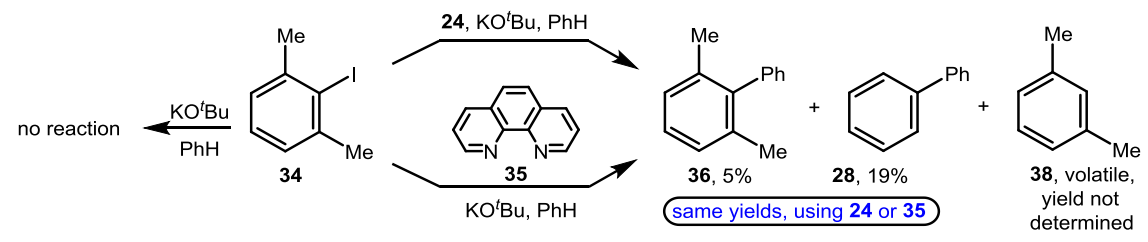

Scheme 9 - Reaction of 2,6-dimethyliodobenzene 34 


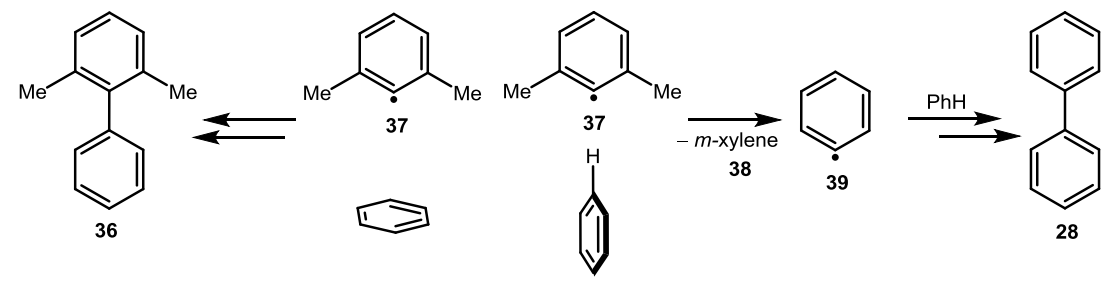

Scheme 10 - Different pathways of reaction for 2,6-dimethylphenyl radical 37

2.2 Dimerisation of phenanthroline and pyridine affords organic electron donors

With substrate $\mathbf{3 4}$ now identified as a probe for electron transfer initiation, we were curious to test whether the phenanthroline conditions would indicate electron transfer, or whether a different mechanism would be required. Reaction of substrate 34 with 1,10-phenanthroline $35(20 \mathrm{~mol} \%)$ and potassium tert-butoxide (2 equiv.) in benzene produced coupled products 36 (5 \%) and biphenyl 28 (19\%) not only in the same ratio, but in the same yields as seen with salt 24. This supported the idea that electron transfer was involved in initiation when phenanthroline 35 was the additive. The question was: how could the presence of phenanthroline lead to formation of an electron donor ${ }^{15}$

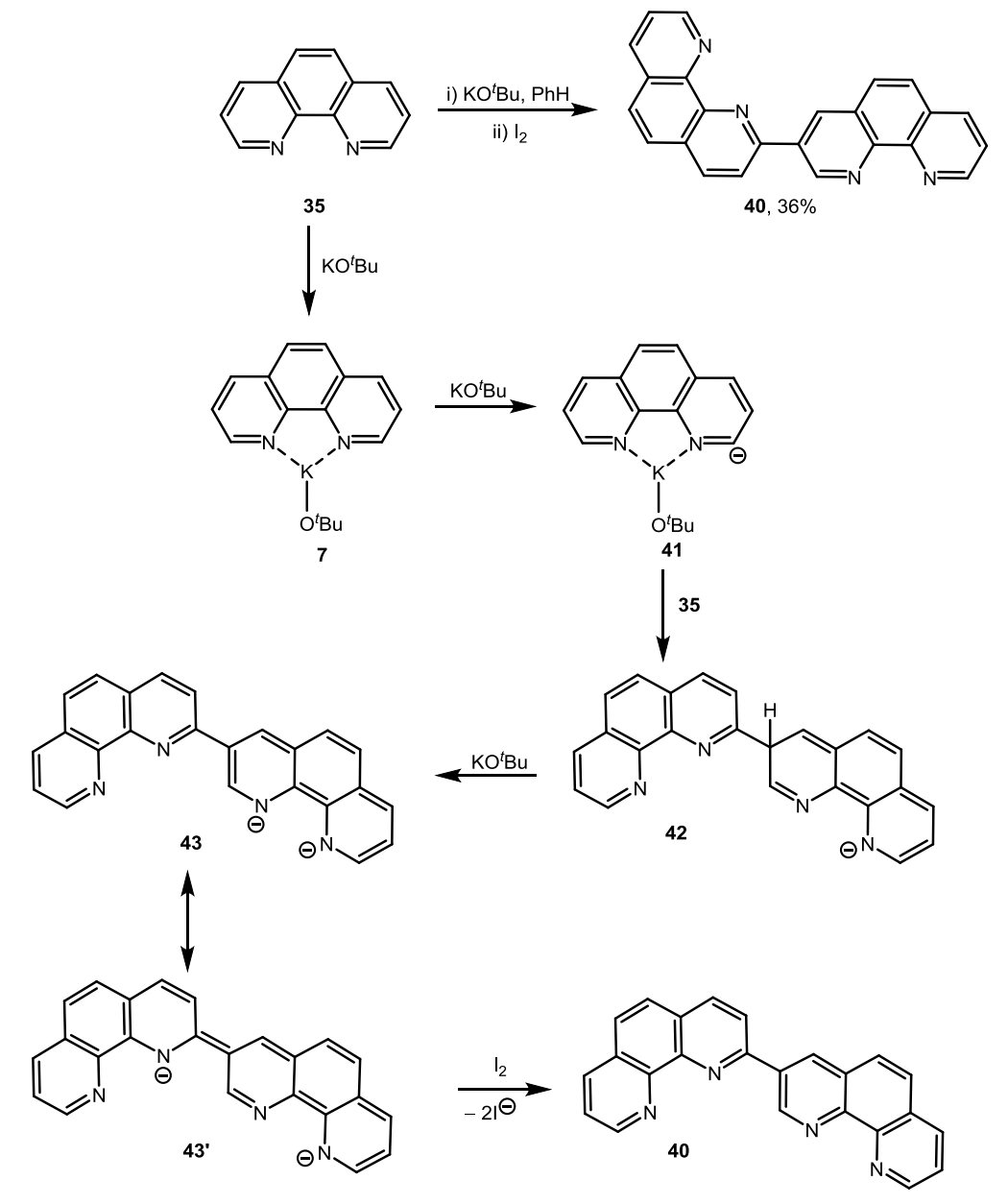

Scheme 11 - Formation of phenanthroline dimer 43 as an in situ electron donor ${ }^{9}$ 
These phenanthroline reactions always gave rise to a dark-green, almost black, precipitate. ${ }^{9,15}$ To find out what was the origin of this precipitate, phenanthroline 35 and potassium tert-butoxide were heated in the absence of the haloarene substrate, and still gave rise to the formation of the dark-green solid. When this solid was exposed to air, it was found to be pyrophoric. The experiment was repeated and this time the green solid was instead quenched under milder conditions with iodine (as an electron acceptor), leading to isolation of phenanthroline dimer $\mathbf{4 0}$ (Scheme 11). Here, 35 complexes to potassium tertbutoxide to form 7, which is subsequently deprotonated to form anion $\mathbf{4 1}$. Anion $\mathbf{4 1}$ can then act as a nucleophile and attack at the 3-position of another molecule of phenanthroline $\mathbf{3 5}$ to form intermediate $\mathbf{4 2}$ which, upon further deprotonation, forms dianion $\mathbf{4 3}$. The similarity of 43 to other super electron donors, such as 27 , is clear, as they contain an electron-rich alkene which is capable of donating an electron to an aryl iodide to initiate the BHAS cycle. This provides an explanation for initiation occurring in Shi's and Shirakawa and Hayashi's work.

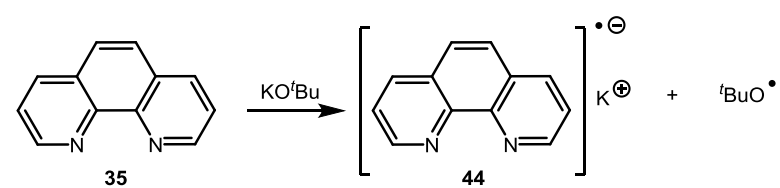

Scheme 12 - Jutand and Lei's suggestion for the role of phenanthroline ${ }^{17}$

Electron transfer from $\mathrm{KO}^{t} \mathrm{Bu}$ to 1,10-phenanthroline complex was also proposed by Wilden et al. ${ }^{16}$ and by Jutand, Lei et al. ${ }^{17}$ Jutand and Lei used electrochemical methods and electron paramagnetic resonance (EPR) spectroscopy to determine that radicals are present when $\mathrm{KO}^{t} \mathrm{Bu}$ and 1,10-phenanthroline react with each other. They found that the combination of these two reagents led to an EPR signal, consistent with the formation of radicals, and proposed that these radicals must be the relatively long-lived species 44, formed from electron transfer from the butoxide anion to phenanthroline 35 (Scheme 12). They proposed that this species is the one that then reduced the aryl iodide to an aryl radical, and initiated the coupling reaction. Their EPR spectrum is similar to that of a phenanthroline radical anion, but the asymmetry of the spectrum would be more consistent with the presence of two similar, but not identical, radical anions (see below). 

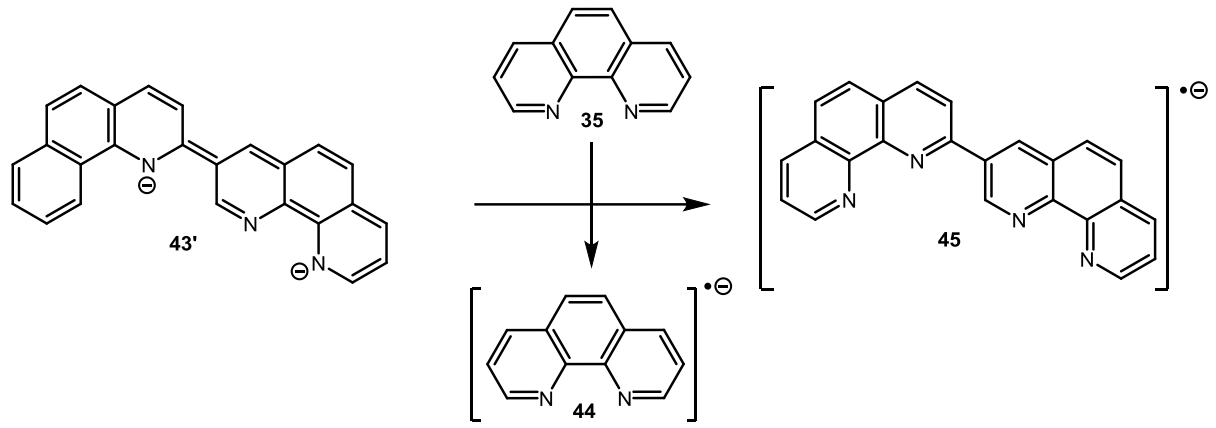

Scheme 13 - Murphy's proposal for the formation of radicals with phenanthroline 35 and $K \mathrm{O}^{t} \mathrm{Bu}$

Moreover, their electrochemical studies do not support their proposal, as they show that the tert-butoxide anion (with an oxidation potential of $+0.10 \mathrm{~V}$ vs. SCE in DMF) is not capable of reducing aryl iodides (reduction potential of $-2.0 \mathrm{~V}$ vs. SCE in DMF). It is therefore unlikely that the butoxide anion will reduce phenanthroline (first reduction potential of $-2.06 \mathrm{~V} v \mathrm{vs}$. SCE in DMF) as the authors suggest. The authors propose that this reduction might occur due to the formation of a phenanthroline- $K \mathrm{O}^{\mathrm{t}} \mathrm{Bu}$ complex where the complexation with a potassium cation brings the butoxide close to the phenanthroline, aiding the electron transfer.

Murphy et al. have suggested that if the phenanthroline dimer $\mathbf{4 3}$ forms, then this is a strong enough electron donor to reduce a neutral molecule of phenanthroline 35 (reduction potential of $-2.05 \mathrm{~V}$ vs. SCE in DMF) to its radical anion 44, and this co-existence of the two radical anions $\mathbf{4 2}$ and $\mathbf{4 5}$ is the reason for the observation of radical species in the complex EPR spectra of Jutand and Lei (Scheme 13).

This use of phenanthroline $+\mathrm{KO}^{t} \mathrm{Bu}$ as a donor has recently been deployed in further coupling reactions. ${ }^{18}$

All of the discussions above relate to ground state reactivity, but it should be borne in mind from the work of Yuan et al. ${ }^{19}$ that irradiation of the phenanthroline/KO'Bu system with a strong source of visible light can lead to direct electron transfer from $\mathrm{KO}^{t} \mathrm{Bu}$ to phenanthroline.

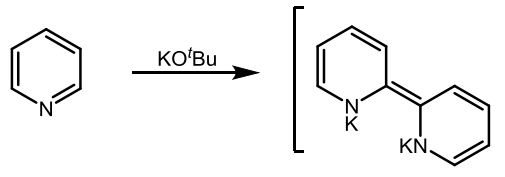

46

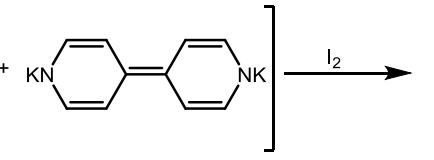

47
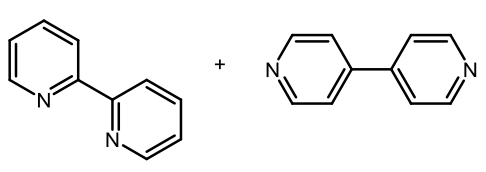

48

traces formed - mixture analysed by GCMS and ${ }^{1} \mathrm{H}$ NMR and compared with authentic samples 
This phenanthroline example provided further evidence that an organic electron donor could be the initiator for the coupling reaction, and so this became a theme in our work. The next example was pyridine, which had been used as an initial substrate by Itami and which was a key solvent in the results of Charette et al. Structural similarity meant that pyridine was likely to behave like phenanthroline, and so it was treated with potassium tert-butoxide followed by quenching with iodine. This led to dimeric products 48 and 49 , analogous to those seen for phenanthroline, albeit in much lower yield. Therefore, $\mathbf{4 6}$ and $\mathbf{4 7}$ are produced in situ and act as electron donors to initiate coupling. Thus, it seemed that initiation through in situ formation of organic electron donors could rationalise the coupling results of Itami, Shi, Shirakawa and Hayashi, and Charette.

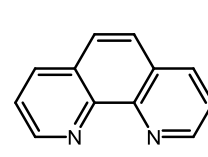

35

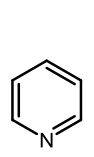

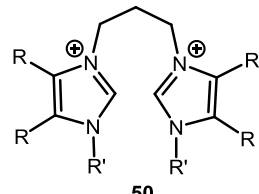

50

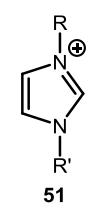<smiles></smiles><smiles>[R]CO</smiles><smiles>CCOC(=O)C(OCC)OCC</smiles><smiles>CNCCNC</smiles>

56

57<smiles>[R]NC1CCCCC1N[R]</smiles>

$\mathbf{5 8}, \mathrm{R}=\mathrm{H}$
$\mathbf{5 9}, \mathrm{R}=\mathrm{Bz}$<smiles>CC(C)=C1C=CC(C(C)=c2ccc(=C(C)C)[nH]2)=N1</smiles>

63

62<smiles>OC1CCN2Cc3ccccc3N=C12</smiles><smiles>CNc1ccc2cccc3c2c1C(=O)C=C3</smiles>

61<smiles>CN(C=O)CCN(C)C=O</smiles>

67

66<smiles>O=C(O)C1CCCN1</smiles>

68<smiles>Oc1c(-c2cn3ccccc3n2)ncc2cccnc12</smiles><smiles>CCNC(=O)NCC</smiles>

69

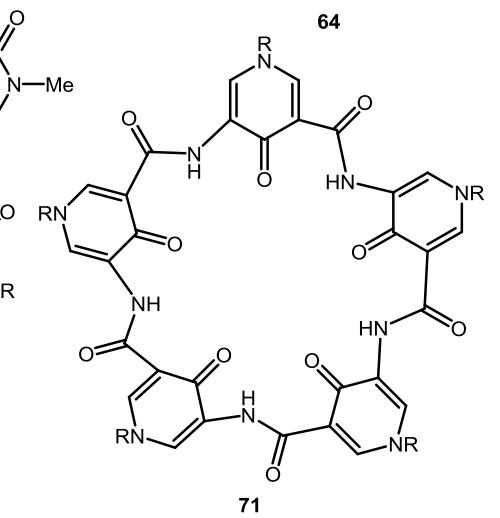

Figure 1 - A selection of additives that promote coupling reactions

A wide range of other organic additives is known to promote the coupling of iodoarenes to arenes, including alcohols, amines, amino acids, pyridinols, formamides, and DMSO, amongst others. (Figure 1). The role of a large number of these additives was identified by Murphy et al. ${ }^{9,15}$ It was proposed that these additives react with $\mathrm{KO}^{t} \mathrm{Bu}$ to form electron donors, and it is these electron donors which initiate the coupling reactions. 
The current list features some common themes. Phenanthroline 35 and pyridine, 2, just discussed, are electron-poor heterocycles that undergo deprotonation followed by dimerization. Imidazolium salts $\mathbf{5 0}$ and $\mathbf{5 1}$ also undergo dimerization following deprotonation but, in this case, an N-heterocyclic carbene is an intermediate. The zwitterionic heterocycle, $52,{ }^{20}$ is in the same family, since it is known to undergo decarboxylative dimerization to afford species 74, featuring an electron-rich alkene (Scheme 15). Product $\mathbf{7 4}$ is also a hydrazine, where deprotonation of the $\mathrm{NH}_{2}$ group(s) could enhance the electron donor nature of the compound (see below for phenylhydrazine 61).

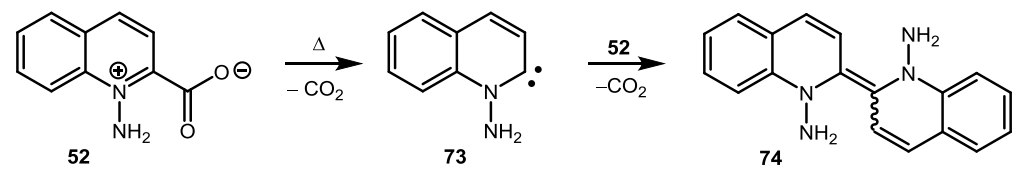

Scheme 15 - Formation of electron donor 74

2.3 Primary and secondary alcohols, 1,2-diols and diamines are oxidised by loss of hydrides; the products are precursors to organic electron donors

Simple aliphatic alcohols ${ }^{21}$ (not tertiary) 53 and 1,2-diols such as 1,2-dihydroxycyclohexane ${ }^{4}$ (54, both cis- and trans- isomers) form in situ electron donors on treatment with $\mathrm{KO}^{t} \mathrm{Bu}$. Thermal studies on cyclohexanediols $\mathbf{5 4}$ showed oxidation to ketone $\mathbf{7 6}$ by hydride ion expulsion (Scheme 16). ${ }^{15}$ The same occurs for monoalcohols 53. Alkoxides 75 are normally oxidised to ketones via the Oppenauer oxidation, but it was shown many decades ago by Woodward et al. that hydride loss also occurred on heating with potassium tert-butoxide in toluene. ${ }^{22}$ Deprotonation of the resulting ketone $\mathbf{7 6}$ then gave enolates of type $\mathbf{7 7}$ and/or $\mathbf{7 8}$, which are likely initiators of electron transfer. It is proposed that $\mathbf{7 8}$ is a better electron donor than 77, as it features a more electron-rich alkene. The deprotonation states of these enolates have not been explored; both may form dianions by a second deprotonation on the hydroxyl group.

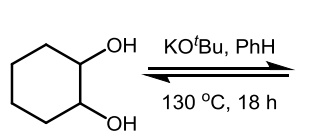

54

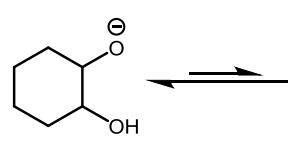

75

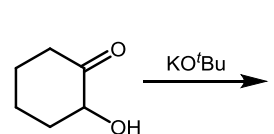

76

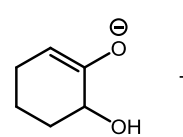

77

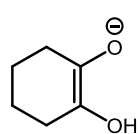

78

Scheme 16 - Formation of Electron Donors 77 and 78 from 54

Previous reports by Bunnett, Scamehorn and Rossi had shown that enolates of simple ketones such as pinacolone or acetone can act as efficient electron donors to aryl halides in ground-state $\mathrm{S}_{\mathrm{RN}} 1$ reactions, and this explains their facilitation of coupling reactions here. ${ }^{23-25}$ Esters such as $\mathbf{5 5}$ form enolates that are substituted by additional electron-releasing ethoxy groups and so it is not too surprising that they are particularly effective as electron donors. 
DMSO 56 has also previously been reported to act as an electron donor to aryl halides via formation of the dimsyl anion. ${ }^{26}$

Simple amines, such as di-n-butylamine were found to exhibit no activity in the coupling of haloarenes to arenes; however 1,2-diamines such as $N, N$-dimethylethylenediamine 57 , and 58 formed effective electron donors (Scheme 17). ${ }^{4}$ Cyclohexane-1,2-diamine 58 was precursor to one of the best electron donors, allowing the coupling of 4-iodotoluene $\mathbf{7 9}$ to benzene to give 4-methylbiphenyl 80 in $89 \%$ and $90 \%$ yields for the trans- and cis- isomers respectively.

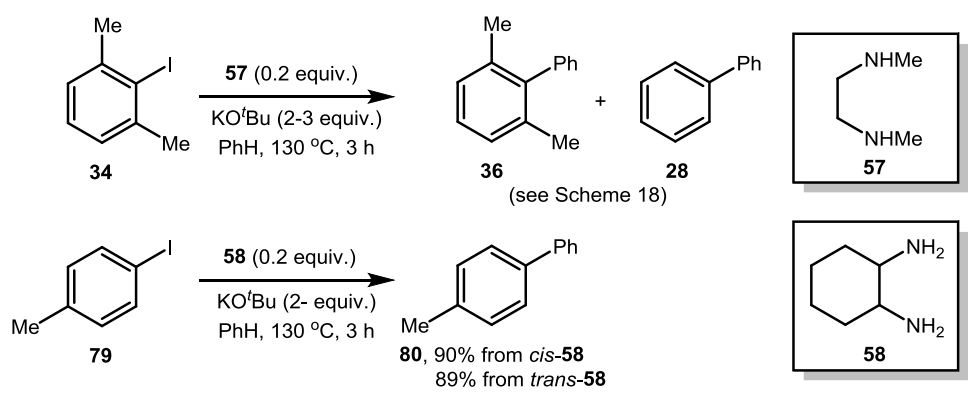

Scheme 17- Amine additives 57 and 58 in transition metal-free coupling reactions

The mechanism proposed for the formation of the active electron donor from amines involves the generation of the corresponding imine 81 from amine 57 by deprotonation and expulsion of a hydride. Upon deprotonation of 81, electron-rich alkene 82 can be formed, and this is proposed as an electron-donating species. This is further backed up by use of

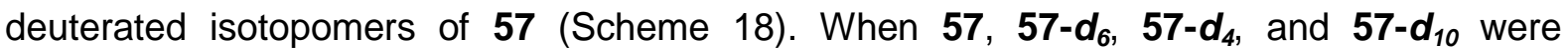
compared in side-by-side reactions involving coupling of iodoarene $\mathbf{3 4}$ to benzene, 57 outperformed all of the deuterated analogues, with $54-d_{4}$, and $54-d_{10}$ returning only trace amounts of coupled products. This is consistent with the cleavage of a methylene $\mathrm{C}-\mathrm{H}$ (or C-D) in the diamine being involved in the rate determining step of the initiation, in line with Scheme 18.

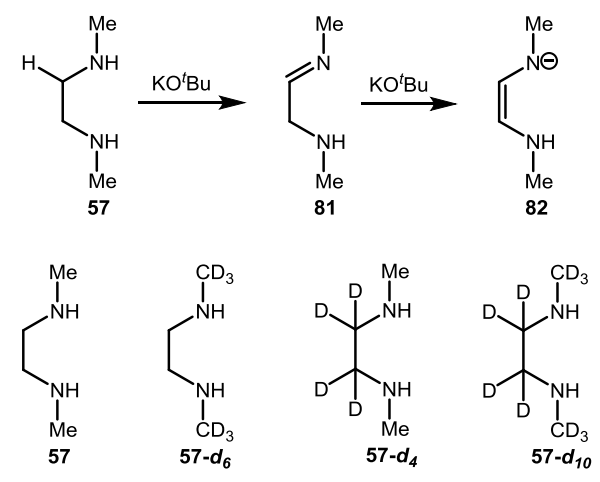

Scheme 18 - Transformation of additive 57 and listing of isotopomers deployed to explore mechanism. 
The mechanism of the diamine initiation was also studied by Jiao et al., who proposed a modified and refined mechanism after experimental and computational studies (Scheme 19). ${ }^{27}$ They proposed that, after formation of aryl radicals had started, the diamine $\mathbf{5 7}$ acted as hydrogen atom donor to aryl radicals $\mathbf{1 0}$, forming radicals $\mathbf{8 3}$ and/or $\mathbf{8 4}$, which undergo deprotonation by $\mathrm{KO}^{\mathrm{t}} \mathrm{Bu}$ to form radical anion $\mathbf{8 5}$.

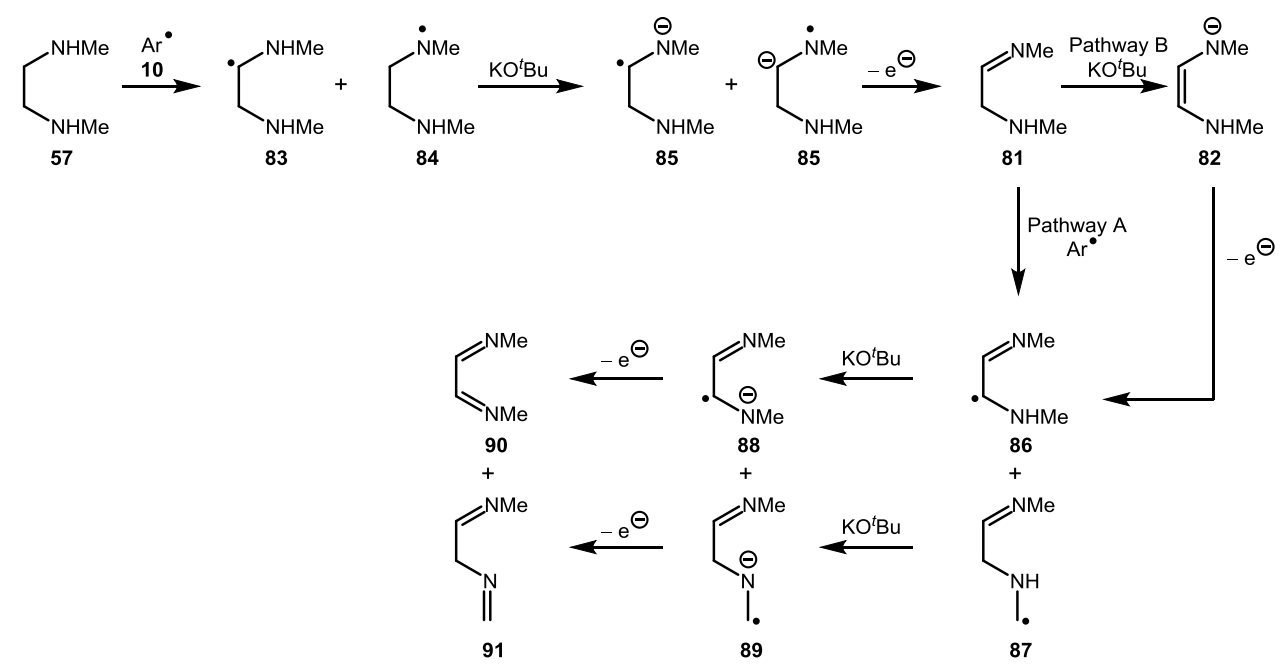

Scheme 19 - Jiao's proposal for initiation with diamine $57^{27}$

This radical anion $\mathbf{8 5}$ can then transfer an electron to the aryl iodide $\mathbf{8}$ to form the aryl radical 10 and join in the initiation of the reaction. The resulting compound $\mathbf{8 1}$ can then either transfer a hydrogen atom to an aryl radical to form the arene and radicals $\mathbf{8 6}$ and/or $\mathbf{8 7}$ via pathway A, or can be deprotonated to form electron-rich alkene $\mathbf{8 2}$. Species 82 can also transfer an electron to the aryl iodide to initiate the coupling reactions, as previously proposed by Murphy et al., via pathway B. The resulting radicals 86 and/or 87 can be deprotonated and generate radical anions $\mathbf{8 8}$ and $\mathbf{8 9}$, which are capable of further initiating the coupling reactions by electron transfer, forming imines 90 and $\mathbf{9 1}$.

Developing the theme, Jiao et al. showed that $N$-methylaniline derivatives 60 promote the coupling reaction between aryl iodides and benzene (Scheme 20). ${ }^{28}$ They proposed that deprotonation of $\mathrm{N}$-methylaniline $\mathbf{6 0}$ to form anion 92 occurs, and this species is the active electron donor, donating an electron to the aryl iodide to initiate the chain process. The resulting radical 93, formed after oxidation, can be deprotonated to form radical anion $\mathbf{9 4}$, which can donate a second electron to a second molecule of aryl iodide, resulting in imine 95. This imine could then hydrolyse upon work-up to produce aniline $\mathbf{9 6}$, which was detected in the reaction mixture by GCMS. More recently, Jiao et al. have shown that indoline is an aryl amine precursor to a particularly effective organic electron donor that allows the coupling of aryl chlorides as well as bromides and iodides. ${ }^{29}$ 


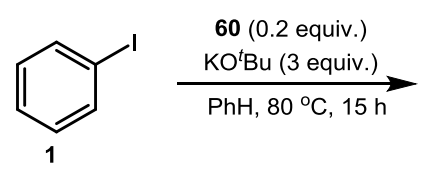<smiles>c1ccc(-c2ccccc2)cc1</smiles>

28, $72 \%$

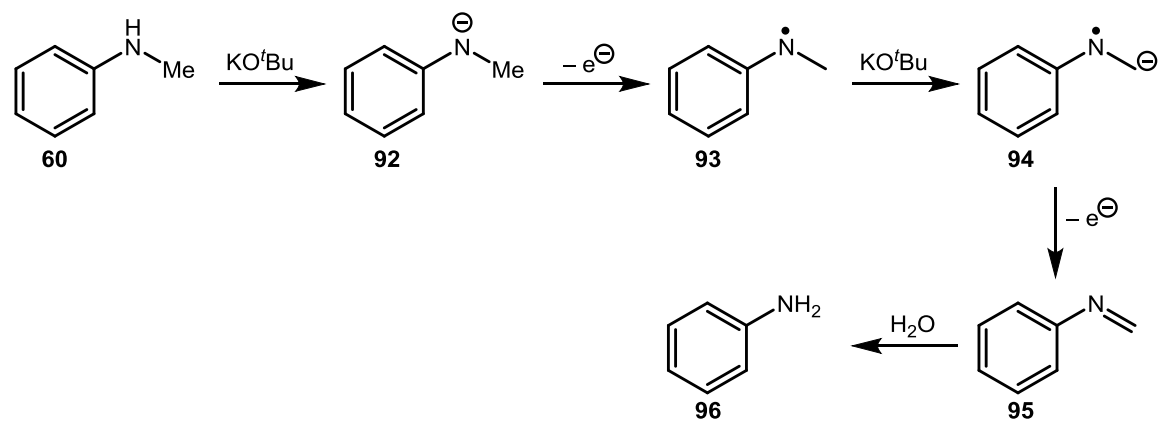

Scheme 20 - Formation of an electron donor from $\mathrm{N}$-methylaniline $60^{28}$

Curran, Studer et al. have shown that phenylhydrazine 61 (Scheme 21) is also effective in the coupling of iodoarenes to benzene. ${ }^{30}$ Phenylhydrazines were proposed to be good initiators due to the a-effect from the lone pair of electrons on the adjacent nitrogen atoms which can stabilise the resulting radical after electron transfer. They propose that deprotonation of phenylhydrazine 61 occurs to form phenylhydrazide $\mathbf{9 7}$, which can then act as an electron donor and form stabilised radical 98 . The aryl iodide radical anion, formed by the electron transfer, can then fragment and propagate as previously, ultimately forming biaryl products.

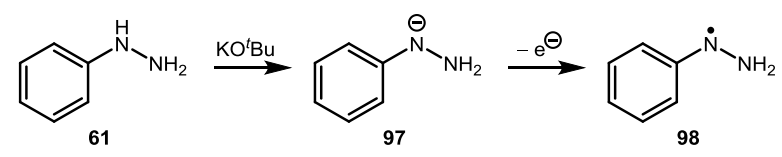

Scheme 21 - Phenylhydrazide 97 as an electron donor

Moving on to pyridinol 62, this compound reacts with $\mathrm{KO}^{t} \mathrm{Bu}$ to facilitate the coupling of haloarenes to benzene (Scheme 22). ${ }^{31,32}$ Extensive investigation showed ${ }^{32}$ that the electron donor resulted from double deprotonation of 62 , forming 99 as the electron donating initiator, reducing both aryl iodides and aryl bromides to aryl radicals.

Kumar et al. reported that alcohol 63 facilitates the coupling of various iodo- and bromoarenes to benzene with $\mathrm{KO}^{t} \mathrm{Bu}$. The authors propose a direct electron transfer from a KO ${ }^{t} \mathrm{Bu}-63$ complex. ${ }^{33}$ However, in view of the structural similarity to pyridinol 62 , we suggest that $\mathbf{6 3}$ is a prime candidate for double-deprotonation to form electron donor $\mathbf{1 0 0}$, complexed with a potassium cation. Similarly, porphyrin 64 has two readily removable protons; doubledeprotonation would afford 101 as an excellent candidate for in situ electron donor to initiation of BHAS reactions. ${ }^{34}$ 

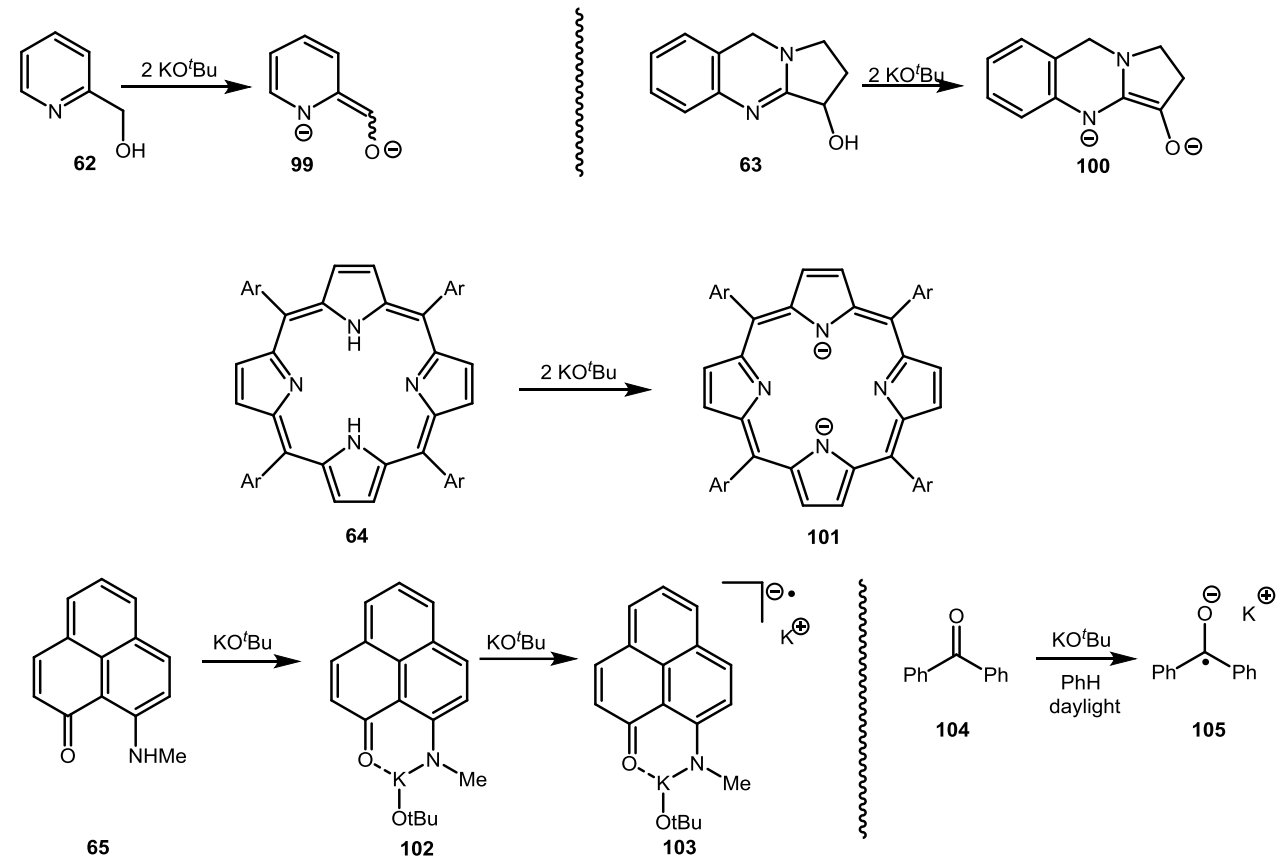

Scheme 22 - Proposed formation of dianionic electron donors 99-101 and 103.

Mandal has vigorously pursued the chemistry of phenalenone 65 and related compounds, and this has been used for the coupling of haloarenes to arenes and to heteroarenes. ${ }^{35,36}$ Treatment with $\mathrm{KO}^{t} \mathrm{Bu}$ results in formation of a complex 102 , where the $\pi$-framework then receives an electron to form a radical dianion 103. This compound is thought to be the active electron donor to aryl halides to initiate BHAS coupling. As 103 is powerful enough to donate an electron to the aryl halide and $\mathrm{KO}^{t} \mathrm{Bu}$ is able to donate an electron to salt 102 , the question arises as to why $\mathrm{KO}^{t} \mathrm{Bu}$ does not directly donate an electron to the aryl halide. This raises the question of whether the conversion of 102 to 103 may be subject to photoassistance from daylight. If so, this would be analogous to the photoreaction of $\mathrm{KO}^{t} \mathrm{Bu}^{19}$ with phenanthroline, and to the conversion of 104 to 105 , reported recently. ${ }^{37}$

\subsection{Dimerisation of DMF and other formamides affords organic electron donors}

Formamides have been shown to be effective additives in the coupling of iodoarenes to benzene. Previous literature had suggested that the anion of DMF (106), formed after deprotonation with $\mathrm{KO}^{t} \mathrm{Bu}$, could act as an electron donor to various substrates, including to aryl iodides ${ }^{38}$ or to another molecule of DMF (Scheme 23). ${ }^{39}$ The latter proposal is untenable in view of recent calculations that indicate a kinetic barrier of $>50 \mathrm{kcal} \mathrm{mol}^{-1} 40$

Murphy et al. proposed ${ }^{41}$ that the anion of DMF 106 can act as a nucleophile to a neutral molecule of DMF 66, forming dimer 108, based on literature precedent. Proton transfer would afford the enolate 109, which has the electron-rich alkene structure reminiscent of a strong electron donor. Alternatively, further deprotonation could afford dianion 110, which 
could be an even more powerful electron donor (Scheme 23). Evidence for the formation of this dimer was given by the use of formamides 111 and 67 (Scheme 24). These formamides were found to be more active in the electron transfer to $\mathbf{3 4}$ than DMF, even at half the

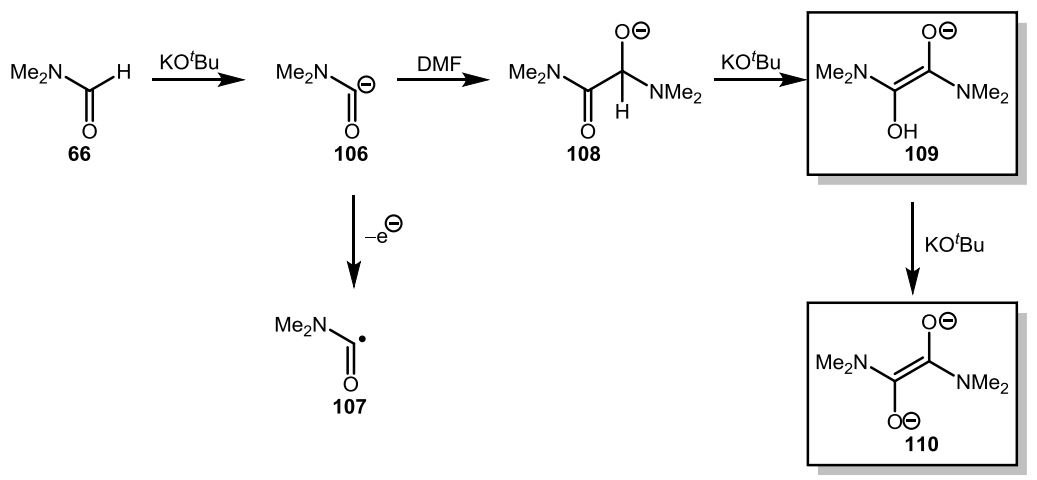

Scheme 23 - Formation of an electron donor from DMF as proposed by Murphy et al. ${ }^{41}$

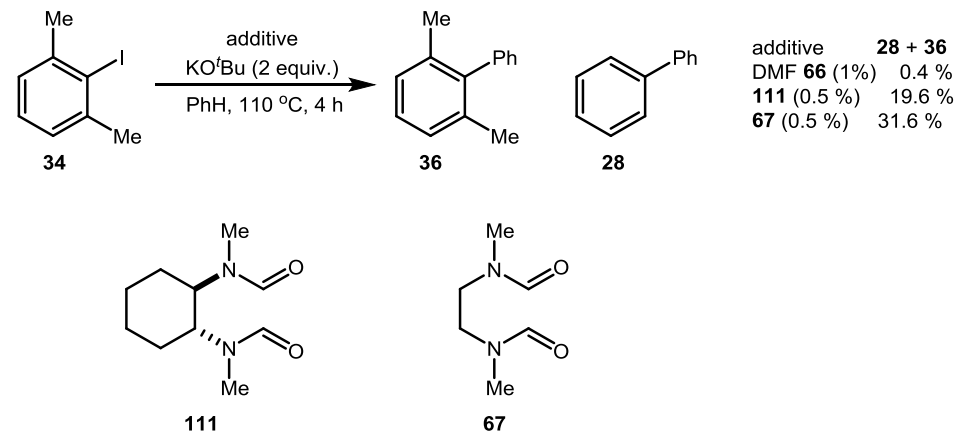

Scheme 24 - Comparison of formamides in electron transfer reactions ${ }^{41}$

concentration, suggesting that facilitating the reaction between two formamide groups really assists the formation of the active electron donor (it would be easier to form a dimer from 111 and 67 than from DMF 66 due to the intramolecular 1,6-relationship of the formamide groups).

2.5 N,N'-disubstituted piperazine-2,5-diones, derived from secondary aminoacids, are precursors to organic electron donors

Secondary amino acids such as proline, 68, are also precursors to efficient electron donors, whereas primary amino acids are less effective and tertiary amino acids are ineffective..$^{4,42}$ As secondary amines are able to undergo condensation reactions with acids on heating, we envisaged forming small amounts of linear oligomers 113 and 114 or cyclic piperazinedione dimers 69. Under the conditions of the coupling reactions, it is thought that small amounts of these compounds could form and that the enolate of such a species, formed by deprotonation, could act as a powerful electron donor. $N, N$-dialkylpiperazinedione 69 was prepared independently and was shown to be a good electron donor ${ }^{15}$ via enolate 115 (Scheme 25), whereas analogue 117 was ineffective, via enolate 118. This is thought to be 
due to the competing deprotonation between the $\mathrm{CH}_{2}$ and the $\mathrm{NH}$ groups. As the $\mathrm{NH}$ is more acidic, that will be the site of deprotonation when an $\mathrm{NH}$ is present. When an amide enolate 118 is formed, it features an electron-poor imine into which some electron density is pumped by the oxyanion. On the other hand, enolate $\mathbf{1 1 5}$ is an alkene rather than an imine, and three electron-rich atoms $(\mathrm{O}, \mathrm{N}, \mathrm{N})$ endow it with electron density. This explains why 115 is an excellent electron donor while 118 does not work as an electron donor.

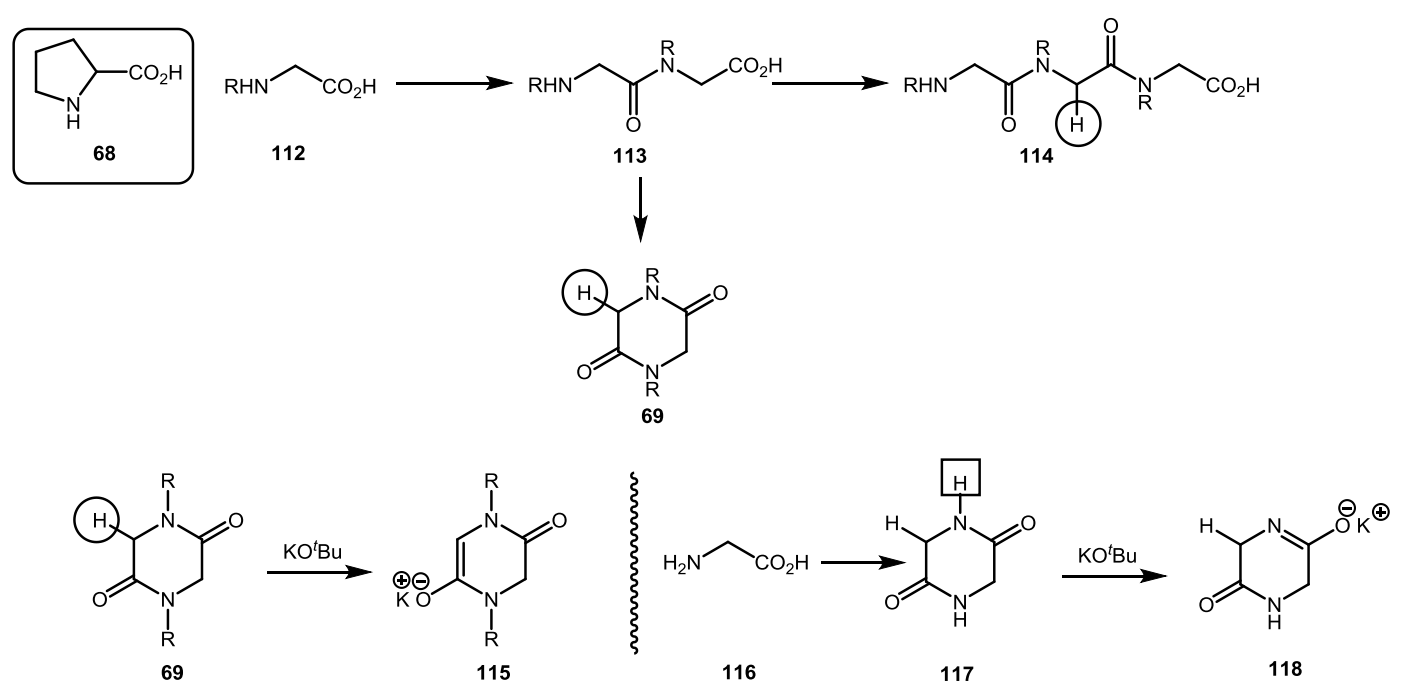

Scheme 25 - Formation of electron donor 115 and structure of inactive piperazinedione precursor $117 .^{40}$

\subsection{Ongoing mechanistic challenges}

Amide deprotonation likely also features in the two examples $70^{43}$ and $71 .^{44,45}$ For the diethylurea $70^{46}$, no mechanistic investigation has been carried out, to our knowledge, although the authors claim that it follows the general guidelines for initiation of the reaction by electron transfer. Substrate $\mathbf{3 4}$ would be the ideal assay for initiation by electron transfer. Additive 71 and related compounds are known to bind potassium cations ${ }^{44,45}$ and are thought to form an electron donor in the presence of $\mathrm{KO}^{t} \mathrm{Bu}$, but the precise structure has not yet been investigated.

More clarity also needs to arise about the mechanism of the coupling reactions that are triggered by $\mathrm{KO}^{t} \mathrm{Bu}$ in the presence of some MOFs. ${ }^{47}$

Finally, additive $\mathbf{7 2}$ is an interesting zwitterion $^{48}$ - the problem is that the structure that represents it in the literature cannot feature the correct bonding. We suggest that the structure may be one or both of the isomeric structures 72 and 119 (Scheme 26). It is easily seen that treating this compound with base would form the radical dianion 120 , which is extremely electron-rich. Loss of an electron enhances the aromaticity of the system, by formation of 121 , supporting the role of 120 as a strong electron donor. 


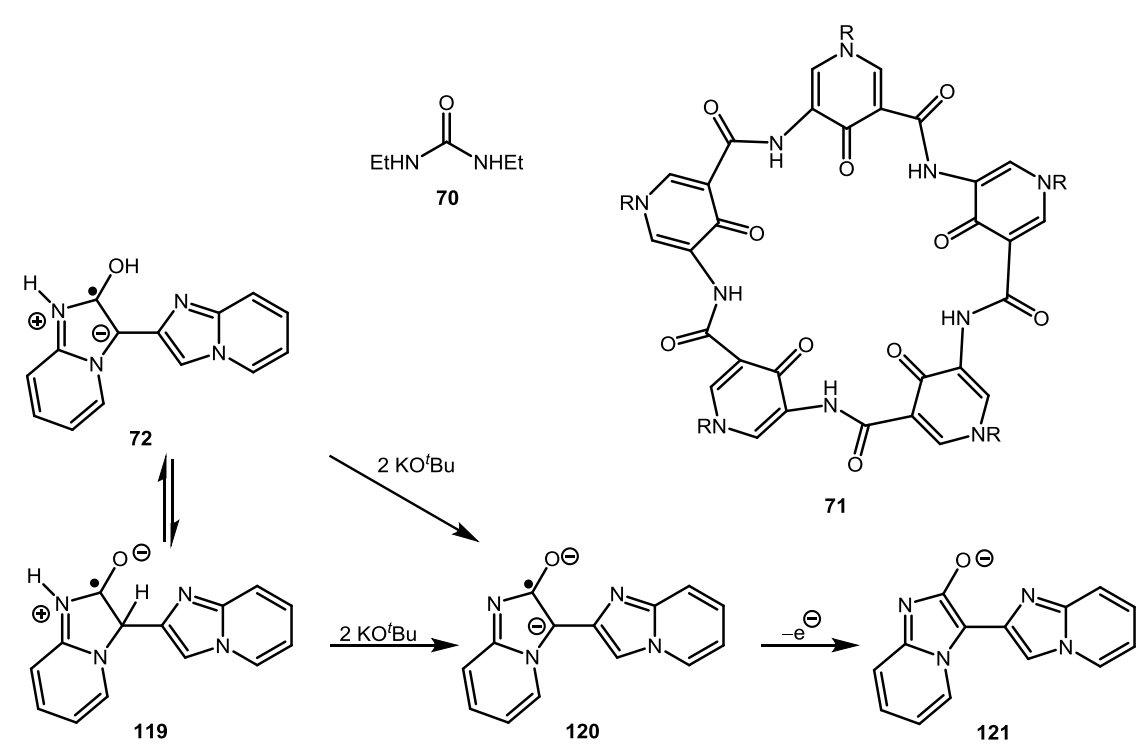

Scheme 26 - Additives 70-72

\section{7 Summary}

This review shows that $\mathrm{KO}^{t} \mathrm{Bu}$, and sometimes $\mathrm{NaO}^{t} \mathrm{Bu}$, reacts with many classes of organic compounds to form strong electron donors that initiate BHAS coupling reactions. The common structural patterns of electron donors are represented in Figure 1. This behaviour is now widely accepted and replaces earlier proposals that $\mathrm{KO}^{t} \mathrm{Bu}$ or $\mathrm{NaO}^{t} \mathrm{Bu}$ were themselves good electron donors in the ground state. That error arose from the early work of Ashby et al. $^{49}$ involving misinterpretation of electron transfer from $\mathrm{KO}^{t} \mathrm{Bu}$ to benzophenone as a ground state reaction. It is not, but it instead results from a visible light-induced photoelectron transfer ${ }^{37}$ within a KO'Bu-benzophenone complex.

Whereas the principles that underlie the formation of organic electron donors are discussed above, the details of structure still need to be better understood. For example, it is not clear why $\mathrm{KO}^{t} \mathrm{Bu}$ is superior to $\mathrm{NaO}^{t} \mathrm{Bu}$ in almost all of the cases discussed. This will be revealed as we understand more about the details of structure. Patil ${ }^{50}$ has identified another factor relating to structure from his computational studies. There, he has explored the effect of aggregation in electron transfer complexes which may be very important for the future.

Chemists have traditionally focussed on reactions that afford high yields of products. This overview indicates that the generation of even very small yields of strong electron donors can divert reactivity into unexpected pathways, when these compounds act as initiators (it is important to stress that they are not catalysts) for BHAS chain reactions. Hence it is not only the high yielding reactions that we need to study. 


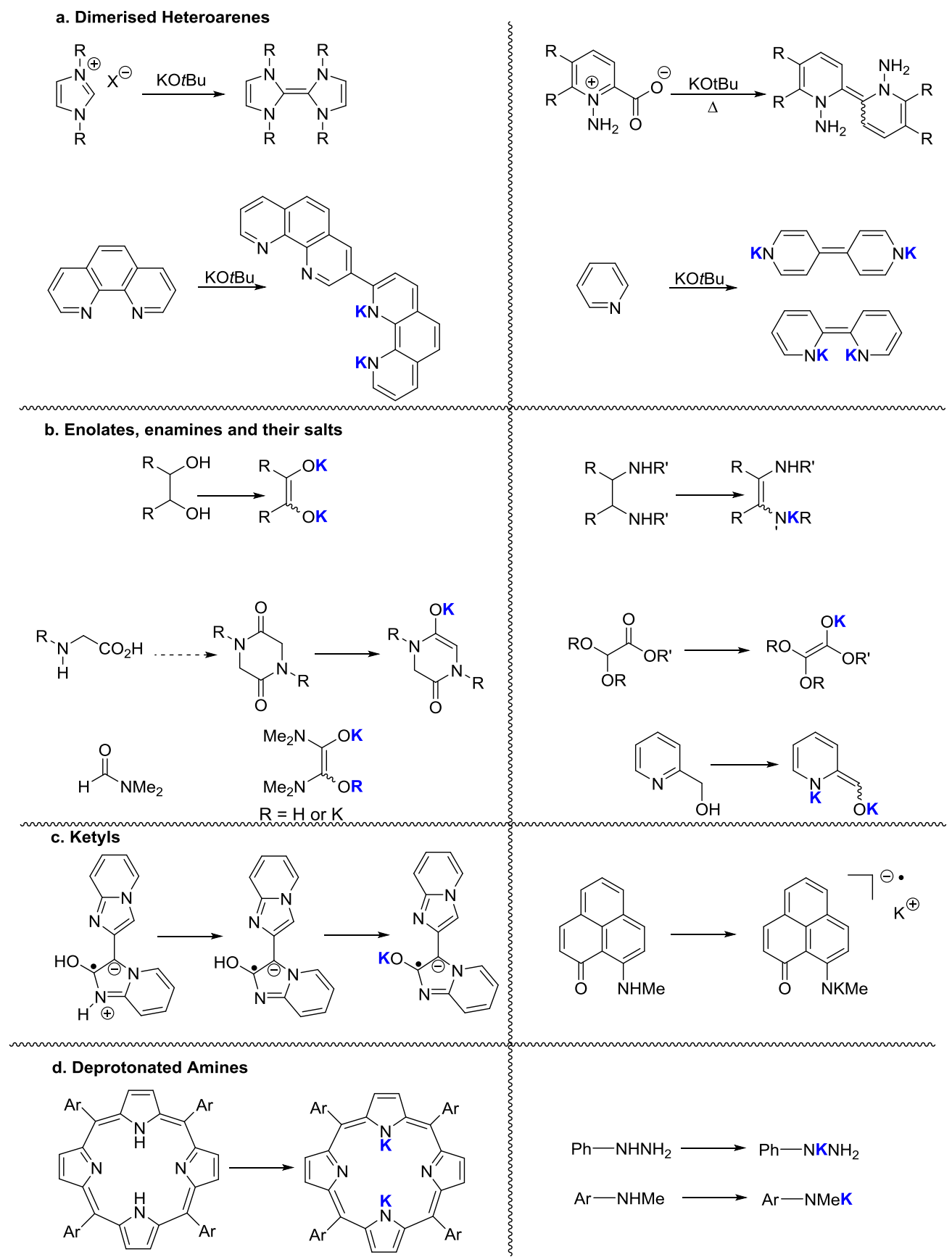

Figure 1. Types of organic electron donors, formed in situ in BHAS reactions, and their chemical precursors.

Acknowledgements. We thank EPSRC, GSK and the University of Strathclyde for funding (AJS).

\section{References.}

1. Yanagisawa S, Ueda K, Taniguchi T, Itami K. Org. Lett. 2008, 10, 4673-4676 
2. Sun C-L, Li H, Yu D-G, Yu M, Zhou X, Lu X, Huang K, Zheng S-F, Li B-J, Shi Z-J. Nat. Chem. 2010, 2, 1044-1049

3. Shirakawa E, Itoh KI, Higashino T, Hayashi T. J. Am. Chem. Soc. 2010, 132, 1553715539

4. Liu W, Cao H, Zhang $\mathrm{H}$, Zhang $\mathrm{H}$, Chung $\mathrm{KH}$, He C, Wang $\mathrm{H}$, Kwong FY, Lei A. J. Am. Chem. Soc. 2010, 132, 16737-16740

5. Roman DS, Takahashi Y, Charette AB. Org. Lett. 2011, 13, 3242-3245

6. Studer A, Curran DP. Angew. Chem. Int. Ed. 2011, 50, 5018-5022

7. Syroashkin MA, Kuriakose EA, Timofeeva VA, Egorov MP, Alabugin IV. Angew. Chem. Int. Ed. 2019, 58, 5532-5550

8. Chen W-C, Hsu Y-C, Shih W-C, Lee C-Y, Chuang W-H, Tsai Y-F, Chen PP-Y, Ong T-G. Chem. Commun. 2012, 48, 6702-6704

9. Zhou S, Anderson GM, Mondal B, Doni E, Ironmonger V, Kranz M, Tuttle T, Murphy JA Chem. Sci. 2014, 5, 476-482 (All minima were optimised using the M06L functional with a $6-311 \mathrm{G}(\mathrm{d}, \mathrm{p})$ basis set. Solvation was modelled implicitly using the CPCM model for benzene as solvent.)

10. Murphy JA, Khan TA, Zhou S, Thomson DW, Mohan M, Angew. Chem. Int. Ed. 2005, $44,1356-1360$

11. Murphy JA, Zhou S, Thomson DW, SchoenebeckF, MohanM, Park SR, Tuttle T, Berlouis LEA. Angew. Chem. Int. Ed. 2007, 46, 5178-5183

12. PG Gassman, HP Benecke, Tetrahedron Lett. 1969, 10, 1089-1092

13. AT Bowne, TA Christopher, RH Levin, Tetrahedron Lett. 1976, 17, 4111-4114

14. S Yamabe, T Minato, A Ishiwata, O Irinamihira, T Machiguchi, J. Org. Chem. 2007, 72, 2832-2841.

15. Zhou S, Doni E, Anderson GM, Kane RG, MacDougall SW, Ironmonger VM, Tuttle T, Murphy JA. J. Am. Chem. Soc. 2014, 136, 17818-17826

16. Cuthbertson J, Gray VJ, Wilden JD. Chem. Commun. 2014, 50, 2575-2578

17. Yi H, Jutand A, Lei A. Chem. Commun. 2015, 51, 545-548

18. Poonpatana P, dos Passos Gomes G, Hurrle T, Chardon K, Bräse S, Masters K-S, Alabugin I. Chem. Eur. J. 2017, 23, 9091-9097

19. Xu Z, Gao L, Wang L, Gong M, Wang W, Yuan, R. ACS Catal. 2015, 5, 45-50

20. Qiu Y, Liu Y, Yang K, Hong W, Li Z, Wang Z, Yao Z, Jiang S, Org. Lett. 2011, 13, 3556-3559

21 Liu W, Tian F, Wang X, Yu H, Bi Y. Chem. Commun. 2013, 49, 2983-2985

22. Woodward RB, Wendler NL, Brutschy FJ. J. Am. Chem. Soc. 1945, 67, 1425-1429

23. Scamehorn RG, Bunnett JF. J. Org. Chem. 1977, 42, 1449-1457

24. Rossi RA, Bunnett JF. J. Am. Chem. Soc. 1972, 94, 683-684 
25. Scamehorn RG, Hardacre JM, Lukanich JM, Sharpe LR. J. Org. Chem. 1984, 49, 4881-4883

26. see Budén ME, Bardagí JI, Puiatti M, Rossi RA. J. Org. Chem. 2017, 82, 8325-8333 and references therein.

27. Zhang L, Yang H, Jiao L. J. Am. Chem. Soc. 2016, 138, 7151-7160

28. Yang H, Zhang L, Jiao L. Chem. Eur. J. 2017, 23, 65-69

29. Yang H, Chu D-Z, Jiao L. Chem. Sci. 2018, 9, 1534-1539

30. Dewanji A, Murarka S, Curran DP, Studer A. Org. Lett. 2013, 15, 6102-6105

31. Wu Y, Choy PY, Kwong FY. Org. Biomol. Chem. 2014, 12, 6820-6823

32. Barham JP, Coulthard G, Kane RG, Delgado N, John MP, Murphy JA. Angew. Chem. Int. Ed. 2016, 55, 4492-4496

33. Sharma S, Kumar M, Kumar V, Kumar N. Tetrahedron Lett. 2013, 54, 4868-4871.

34. Ng YS, Chan CS, Chan KS. Tetrahedron Lett. 2012, 53, 3911-3914

35. Paira R, Singh B, Hota PK, Ahmed J, Sau SC, Johnpeter JP, Mandal SK. J. Org. Chem. 2016, 81, 2432-2441

36. Banik A, Paira R, Shaw BK, Vijaykumar G, Mandal SK. J. Org. Chem. 2018, 83, 3236-3244

37. Nocera G, Young A, Palumbo F, Emery KJ, Coulthard G, McGuire T, Tuttle T, Murphy JA. J. Am. Chem. Soc. 2018, 140, 9751-9757

38. Pichette Drapeau M, Fabre I, Grimaud L, Ciofini I, Ollevier T, Taillefer M, Angew. Chem. Int. Ed. 2015, 54, 10587-10591

39. Wei W, Dong X, Nie S, Chen Y, Zhang X, Yan M. Org. Lett. 2013, 15, 6018-6021

40. Evoniuk CJ, dos Passos Gomes G, Hill SP, Fujita S, Hanson K, Alabugin IV. J. Am. Chem. Soc. 2017, 139, 16210-16221

41. Barham JP, Coulthard G, Emery KJ, Doni E, Cumine F, Nocera G, John MP, Berlouis LEA, McGuire T, Tuttle T, Murphy JA. J. Am. Chem. Soc. 2016, 138, 7402-7410

42. Tanimoro K, Ueno M, Takeda K, Kirihata M, Tanimori S. J. Org. Chem. 2012, 77, 7844-7849

43. Zhao H, Xu X, Wu W, Zhang W, Zhang Y, Catal. Commun. 2018, 111, 95-99.

44. Zhao H, Shen J, Guo J, Ye R, Zeng H. Chem. Commun. 2013, 49, 2323-2325

45. Zhao H, Shen J, Ren C, Zeng W, Zeng H. Org. Lett. 2017, 19, 2190-2193

46. H. Zhao, X. Xu, W. Wu, W. Zhang and Y. Zhang, Catal. Commun., 2018, 111, 95-99.

47. Liu H, Yin B, Gao Z, Li Y, Jiang. Chem. Commun. 2012, 48, 2033-2035

48. Yong G-P, She W-L, Zhang Y-M, Li Y-Z. Chem. Commun. 2011, 47, 11766-11768

49. Ashby EC, Argyropoulos JN. J. Org. Chem. 1986, 51, 3593-3597.

50 Patil M. J. Org. Chem. 2016, 81, 632-639 


\section{Graphical abstract.}

The role of organic electron donors in the initiation of BHAS base-induced coupling reactions between haloarenes and arenes

A. J. Smith, D. L. Poole, J. A. Murphy

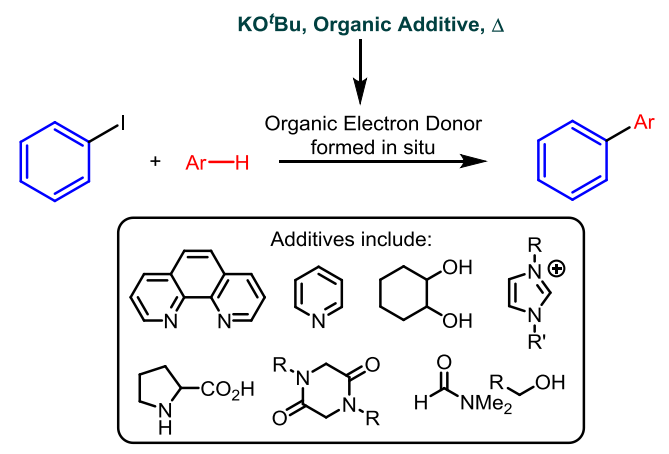

